\title{
Language Maintenance of Tanjung Pinang Chinese Students at Bina Nusantara University
}

\author{
Susanty, R R Simanjuntak* \\ English Department, Faculty of Humanities, Bina Nusantara University, Jakarta, Indonesia \\ *Corresponding author email: risarsimanjuntak@binus.edu
}

\begin{abstract}
This research was aimed to observe the language maintenance of Tanjung Pinang Chinese Students at Bina Nusantara University. It was a qualitative method by spreading questionnaires to 30 participants of Tanjung Pinang Chinese students at Binus University and doing face to face interview to 5 participants from the total of 30 participants. The research found that Tanjung Pinang Chinese Students at Binus University really value their vernacular and consider it as a cultural wealth that has to be preserved. Even though sometimes they have to shift their language when communicate with those who cannot speak it, it is not the reason for them to not maintain their vernacular. Frequent contact with family and homeland, and keep using the language in every chance are the effective ways to maintain the language. Through the findings, it can be learned that an incentive and willingness to maintain a language comes after the awareness to respect and value it.
\end{abstract}

Keywords: Language Maintenance, Tanjung Pinang Chinese, Bina Nusantara University

\section{INTRODUCTION}

Vernacular Language is the language of a particular group, profession, region, or country, especially as spoken rather than formally written $[1,2,3]$. In addition, vernacular is the term to indicate a language which is used in everyday interaction regardless implying that it is appropriate only in informal domains [4]. Besides, writer also used the theory of Language Repertoire, which is the set of language varieties used in speaking and writing practices of a speech community [5]. The use of Repertoire is related to Domains, which are typical interactions between typical participants in typical setting in a speech community [6].

Language maintenance happens when a speaker, a group of speakers or a speech community continue to use their language in some or all spheres of life despite competition with the dominant or majority language to become the main/sole language [7]. This means that a language will become stronger when it is used more often. There many factors that support language maintenance, such as family ties, frequent contact with homeland, in group marriage, and religious meeting or other activities that required the use of vernacular or minority language $[8,9]$.

With this regard, this present study was interested in investigating the ways students maintain their vernacular language by answering two questions, (1) what ways do the students.

\section{LANGUAGE MAINTENANCE AND PREVIOUS STUDIES}

Language Shift is defined to be the replacement of one language by another as a primary means of communication and socialization within community as stated by Mesthrie et all (2002, p.253). When Language Shift happens, it tends to shift to the dominant language. Holmes (2008) pointed out there are many factors contributed in Language Shift, shift such as the new language is more appealing because it can give power for those who speak the language. The second factor is when there is no domains to use it, in which there is no opportunity for people to speak the minority language because they have no partners that can interact with them using the minority language, and this situation forces them to shift the minority language into another language that commonly use in their domains. The other factors that also considered as a unit of factors that force people to shift their language are nobody understand and speak it, no reading materials written it and no radio or television programs use the language. Those factors are the situation that force people to commit into language shift, and generally are occurring toward immigrants.

Besides the theories that have been mentioned above, writer also collected other theories such as Language Choice and Language Loss to support this study. Language Choice is available options in certain situation where people can choose the language they would like to use according to Fasold (1984) and Holmes (2001). Refer to this definition, Language Choice actually relates to 
Repertoire and Domains. Therefore, Language Choice itself is determined by Domains that identified with family, friendship, religion, education and occupation. Meanwhile, Language Loss is a situation when someone uses his or her own vernacular language in a fewer and fewer domains regarding to Holmes (2001) and Fishman (1964). Holmes and Fishman also pointed out several factors that contribute to language loss. Firstly, language loss happens because the native speakers of a language have adopted another language and use the adopted language more often rather than the native language. Secondly, as a result of limited domains to use the vernacular, the speakers think that there is no more reason to use the language. Thirdly, the owners of the vernacular have no effort to maintain the language.

According to previous study conducted about Language Maintenance of Chinese Language in Glodok area, it was found that the Chinese people are difficult to mix with natives since the tradition of their social system is venerable and impressive [1]. Therefore, the culture was believed to be what shaped their identity, especially for maintaining language [1]. Other previous study on language maintenance and language shift experienced by 50 Pontianak Chinese students found that these students struggled to maintain their vernacular [2]. At times these students had to shift it into different repertoires for certain situation [2].

\section{RESEARCH METHODS}

The study was conducted at Bina Nusantara University. The selected students would be from Tanjung Pinang. Most of Binus students who come from Tanjung Pinang are Chinese. In Fact, it is really easy to notice the Tanjung Pinang Chinese students of Binus because of their very strong vernacular accent even when they are speaking in Bahasa Indonesia. It is known that their very strong accent of the vernacular even though they have moved to Jakarta is due to their frequent use of the vernacular in every possible opportunity. This is because of vernacular is their daily language in their hometown, and they still use it with acquaintances who speak it too when they are living in Jakarta.

The study about Language Maintenance of Tanjung Pinang Chinese students at Bina Nusantara University was started from a preliminary observation made writer, where writer often sees how the Binus Tanjung Pinang Chinese students interact with their friends in their community in the campus areas. Afterwards, what makes writer curious to conduct this study is writer discovered that they always use vernacular when socializing even in the campus areas and whenever they meet people who can speak their vernacular. After this observation, writer started to collected literature reviews that related to Language Maintenance. After that, writer started to devise a procedure to conduct this study, and this following will discuss clearly how that procedure be conducted.

First of all, writer did a survey toward 30 Bina Nusantara Tanjung Pinang Chinese students from any major in Binus Kemanggisan Campuses. This research is a qualitative research that was done in two steps which are questionnaires and interview. The chosen 30 participants of the questionnaires are active undergraduate students of Binus University, who are Binusian 2016 (the final year Binus students) until Binusian 2019 (the first year entrance Binus students). These 30 participants are Tanjung Pinang Chinese students who speak their vernacular fluently. The questions in the questionnaires are mostly related to Language Maintenance, such are how the ways the maintain their ability to speak vernacular when they are living in Jakarta, what reasons make them want to maintain the vernacular, and how the ways they avoid language shift when they are living Jakarta in which their vernacular is obviously not the majority language.

When the first research had been done, which was the questionnaires, then result will be analyzed by relating it to the literature reviews that had been collected by writer. The result of the analysis then will be supported with numerical data which shows the result accompanied with detailed percentage. Afterwards, 5 participants will be chosen from 30 participants of the questionnaires. These 5 participants are those who had unique responses on the questionnaires and represent different cases related to language maintenance. Writer will do interview with these 5 chosen participants and the question will be based on each case that represented by each participant. The goals of this interview is to find further and complete result of each case that related to this study, and so do the writer's intention to choose these 5 participants.

After the interview had been done, the writer will do analysis again based on the result of the interview. Finally, writer will conclude the core values of this study which will answer all the problem formulation. After the conclusion had been made, writer will state her suggestion for other researcher who will do same study in the future.

The steps of conducting this research could be seen in Figure1 below: 


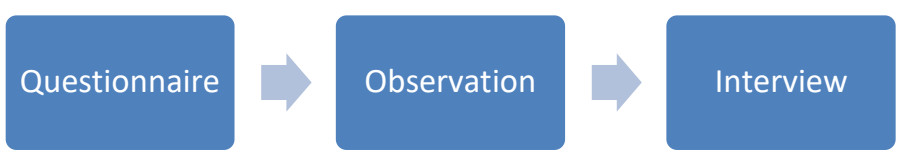

FIGURE 1 Research Procedure

\section{RESULTS AND DISCUSSION}

Results will be presented in two sections, from the questionnaire and from the interview.

\subsection{Results from the Questionnaire}

In this part, writer will state the result of the analysis and the discussion of Language Maintenance of Tanjung Pinang Chinese students at Binus University. From the result of the questionnaires, it is known that 18 persons of the 30 participants or $60 \%$ are males, and 12 persons or $40 \%$ are females. From all the participants data it is known that 10 persons or $33,3 \%$ of the participants are final year students who are Binusian 2016, 5 persons or 16,6\% are third year students or Binusian 2017, 10 persons or $33,3 \%$ are second year students or Binusian 2018, and 5 persons or $16,6 \%$ are first year students or Binusian 2019

This following are the results of the questionnaires. First is about the vernacular language of the participants, which are known that there are 4 different vernaculars among those 30 participants. 25 participants or $83,3 \%$ vernacular is Theo Chew, 2 persons or $6,6 \%$ vernacular is Khek, 2 persons or $6,6 \%$ is Hokkian, and the remaining 1 person or $3,3 \%$ is Cantonese. Therefore, from this result it is concluded that the most spoken vernacular among all the participants is Theo Chew language.

The second question in the questionnaires is about the repertoires among all of the participants, and the result is there are 9 repertoires mastered by the participants. 28 participants or $93,3 \%$ speak Theo Chew, 3 participants or $10 \%$ speak Khek, 4 participants or $13,3 \%$ speak Hokkian, 1 participants or 3,3\% speak Cantonese, 25 participants or $83,3 \%$ speak Mandarin, 28 participants or $93,3 \%$ speak English, 30 participants or $100 \%$ speak Bahasa Indonesia. From this result, it concludes that almost all the participants are able to speak international language such as English, Mandarin and of course all the participants speak Bahasa Indonesia as their national language, and most of the participants speak Theo Chew.

Third question is about Domains of the participants repertoires. Domains is the term to show in what kind of context the repertoires being used, and the available contexts in the questionnaires almost fulfilled all the contexts that being used in family, friendship, education and occupation. Here are the result of the questionnaires that show clearly the Domains of the participants repertoires. Theo Chew is mastered by 28 participants, 26 participants or $92,8 \%$ are using Theo Chew in the context of family, 28 participants or $100 \%$ use it in the context of friendship, while none of the participants use it in the context of education and occupation. Khek is mastered by 3 participants, 2 persons or $66,6 \%$ use Khek in family context, all of the 3 participants of $100 \%$ use it in the context of friendship, and none of them use it in the context of education and occupation. Hokkian is mastered by 4 participants, 3 persons of them or $75 \%$ use it in the context of family, and all of them or $100 \%$ use it in the context of friendship, while none of them use it in neither education nor occupation context. Cantonese is only mastered by 1 person who definitely also the vernacular owner of this language, it is used in the context of family and friendship, but not in the context of education and occupation. Melayu is mastered by 2 participants and only used by both of them in the context of family and friendship, while no one used it in the context of education and occupation. Bahasa Indonesia is mastered by all the 30 participants, only 1 used it in the context of family, all of them used in the context of friendship and education, and only 5 participants or $16,6 \%$ used it in the context of occupation because not all of the participants already have a job. Mandarin is mastered by 25 participants, 10 of them or $40 \%$ use it when interacting with family, 25 persons or $100 \%$ use it to socialize with friends and also use it in the 
context of education, while 5 persons or $20 \%$ use it in the context of occupation. English is mastered by 28 participants, 1 person use it when socialize with family, 28 persons or $100 \%$ use it in the context of education and friendship, while 5 persons or $17,8 \%$ use it in the context of occupation. Japanese language is mastered by 2 participants, 1 of them use it in the context of education, and the another 1 only use it in the context of friendship, while none of them use it in the context of family and occupation. From this result, it concludes that the minority languages which are the vernacular languages are often used in the informal context such as family and friendship, while the majority languages such as English, Mandarin and Bahasa Indonesia are used more often in the formal context like education and occupation, and also use in every context either formal or informal.

Fourth question is about the importance of vernacular for the participants, the scale that given by writer in the questionnaires are starting from the option of very important until very not important. This following are the result of this question, 14 participants or $46,6 \%$ who said that vernacular is very important for them, 13 participants or $43,3 \%$ said that vernacular is important, 3 participants or $10 \%$ said that vernacular is quite important, and none of them said vernacular is not important nor very not important. From this result, writer concludes that most of the participants even almost all the participants are really valuing the vernacular, and this conclusion also supported by the option of not important and very not important that no one choose both of these options.

The fifth question is about the length of stay of the participants in Jakarta, and the result is vary. 5 persons or $16,6 \%$ have already been living in Jakarta less than one year, 9 persons of $30 \%$ have already been living in Jakarta for one until two years, 14 persons or $46,6 \%$ have already been living in Jakarta for three years until 4 years, and 2 persons or $6,6 \%$ have already been living in Jakarta for 5 years or more. Referring to this result, writer concludes that how long the participants stay in Jakarta cannot be only determined by their year of entrance as a Binusian.

The sixth question is about the participants' frequency of vernacular usage when they are living in Jakarta. 10 participants or $33,3 \%$ answered that they are very often to use the vernacular when they live in Jakarta, 13 participants or $43,3 \%$ answered often, 5 participants or $16,6 \%$ answered rarely, 1 participants said very rare, and 1 participants said never. Looking at the result, writer concludes that the Language Maintenance of Tanjung Pinang Chinese students is very strong, which is can be seen from the percentage of participants who said very often and often to use their vernacular even though they have moved to Jakarta. It means that most of the participants are still valuing their vernacular and proud of using it even though it becomes the minority language in Jakarta. This actually fits the statement of Davies et all (2004) that Language Maintenance can be defined as a situation in which a group of minority language continuously using that language.

The seventh question is about the participants' vernacular language distribution when they live in Jakarta, which is with whom they usually talk to using the vernacular in Jakarta. The result is 23 participants or $76,6 \%$ use vernacular when communicate with family in hometown via telephone, 24 participants or $80 \%$ use vernacular when talking to their friend who are coming from the same hometown, 14 participants or $4,6 \%$ usually communicate using vernacular to friends whose vernacular is little bit the same with theirs, 15 participants or $50 \%$ usually use vernacular when talk to whoever that are able to speak their vernacular, and 1 participants left said that he usually uses vernacular to talk with his relation in Jakarta. The sources of vernacular usage are playing huge role in language maintenance. From the data result, it seems that the participants have wide language distribution, not only with family and friends from hometown, but they also communicate with others who can speak their vernacular, and even there is one who has relation in Jakarta that can be a source to socialize using the vernacular.

The eight question in the questionnaires is about the participants' opinion toward the importance of vernacular preservation. There are 5 options in the questionnaires which are very important, important, quite important, unimportant, and very unimportant. From these options, 14 participants or $46,6 \%$ said it is very important, 12 or $40 \%$ said it is important, 4 or $13,3 \%$ said it is quite important, and none choose the remaining two options. This answers of the questionnaires determines the participants attitude toward the vernacular in which they are respecting the vernacular that no one said it is unimportant nor very unimportant.

The ninth question is related to the participants' previous answer about the importance of vernacular preservation, which is about the willingness of participants toward vernacular inheritance and their reasons. 26 participants or $86,6 \%$ answered Yes, 2 participants or $6,6 \%$ answered Maybe, 2 participants 
answered Depends, and no one answered No. This following are their reasons related to their answers, 2 persons said it depends on who is their future husband, 19 persons or $63,3 \%$ said it is an identity and culture that have to be preserved, 7 persons or $23,3 \%$ said because of the vernacular is easy to be spoken, and the 2 remaining persons said it depends on their future environment condition. From this result, writer concludes that the possibility for Tanjung Pinang Chinese students to maintain their language is very big, which is supported by the Yes answer of the participants accompanied with their reasonable reasons.

The tenth or last question is about the participants' conviction related to the questions of vernacular inheritance and the reasons. The result is 17 participants or $56,6 \%$ said they are totally sure, 10 participants or $33,3 \%$ said they are sure, 3 participants or $10 \%$ said they are not really sure, and none of the participants said they are not sure or totally not sure. Looking at the answers that most of the participants said they are totally sure and sure, and compares to the percentage of previous question's answers, writer concludes that again the possibility of Tanjung Pinang Chinese language to be preserved is really big. However, there are still the answers of "not really sure" and "depends" related to the previous question, these answers will be discussed further in the next session of analysis which is the interview result with the chosen participants.

\subsection{Results from the Interview}

This part is particularly discussing about the result of the interview toward the 5 chosen participants, in which each of them represented each case related to Language Maintenance. Firstly, is Juliastina, she thought that vernacular is very important but did not sure that if she could pass down her vernacular to her descendants, because it depends on who is her future husband. What caused her did not sure is because she thought that if her husband were not share the same vernacular, of course she cannot communicate in vernacular with her children at home because her husband will not understand. Nevertheless, she said that even in the end she cannot pass down her vernacular to the descendants, she will make her children learn it from her parents. Looking at Juliastina response, she seemed still struggling to preserve her vernacular by still trying to find a way in order to make her descendants inherit her vernacular. One of factors is family live closer to each other. This finding was in line with previous research [7]. Therefore, despite Juliastina Juliastina cannot make her descendants learn the vernacular straight herself, this problem is solvable since Juliastina has a close relation with her parents that she can make her descendants learn the vernacular from their grandparents.

The second response in the interview is Herick who represented the case of those who really love their vernacular but do not have a supporting environment to communicate using vernacular and it also due to the length of stay in Jakarta. Herick said that vernacular is really important along with the preservation and inheritance. However, what became his obstacle is his length of stay in Jakarta that more than 8 years, thus his friends are mostly in Jakarta that they cannot speak his vernacular. Herick source of speaking the vernacular is only his family. Looking at the case of Herick, Domains do play important role in language preservation. Due to the limited Domains of Herick to use the vernacular, he is so rarely talking using vernacular in Jakarta. Besides this obstacle, Herick said that he would still struggle to maintain his ability to speak the vernacular by having more contact with his family in his hometown. Herick also committed to pass down his vernacular to his descendants in the future, since for Herick the vernacular is a sign and identity as a Chinese.

The third response was represented by Alex who thought that vernacular is very important including the preservation and inheritance to his descendants. However, Alex never use vernacular in Jakarta, because he did not have any friend speak his vernacular. Meanwhile, he felt awkward to talk to his friends using vernacular even he knew that his friends are able to speak the vernacular. This is because of he have already been living in Jakarta for a long time and never speak his vernacular in Jakarta. Nonetheless, he said that it did not mean that he did not want to pass down the vernacular to his descendants. Even though he never use vernacular when living in Jakarta, but he is still using the vernacular when talking to his family. He said that he would also talk to his descendants by using the vernacular once he got married, because for him the vernacular preservation is important and vernacular is a culture that has to be preserved.

The fourth response was represented by Minmin, she presented those participants who did not sure to preserve the vernacular, because they counted it on the future environment condition. Minmin said that vernacular preservation is just quite important, but for herself to do it she would just count it on her future environment condition. She meant that she would do the preservation but it depends on what will she get when she did it. For example, if later on 
in the future she lived in the environment that surrounded by people who speak her vernacular, she would have passed down her vernacular to her children so they would easier to communicate with people around them. However, if what happened next is in the contrary condition, she would not make her children learn it because it will just useless. This is because of Minmin is a very objective-oriented person and she is just taking the vernacular for granted. She said that she would prefer to make her children learn the more universal languages such as English and Mandarin that definitely will easier their life such as easier entrance to workplace and other prospects. For the case presented by Minmin, it concludes that she is actually in the crossing side of Language Shift. This is related to Holmes (2008) that someone conducted language shift is because of the new language is more appealing compares to his/her own language.

The fifth response is represented by Winda who represented those participants who really respect and value their vernacular. Winda said that vernacular is really important along with the inheritance and preservation. Therefore, she said that no matter what the majority languages provide, she would always choose her vernacular since vernacular is very meaningful that the other languages do not have. For her, vernacular determines her identity and where she comes from, and also defines her culture. Thus, the vernacular preservation is a must, and it deserves to be passed down to the descendants.

Referring to each response that represented by these 5 participants, writer concludes that most of the participants are really valuing their vernacular that can be seen from their struggle to maintain the vernacular despite the obstacles they had. Besides, there are also some participants who has already been in the crossing side of language shift. Scrutinizing all the discussion either from the result of the questionnaires or interview, writer concludes that the attitude toward vernacular is the most important key in maintaining a language.

\section{CONCLUSION AND IMPLICATION}

Throughout all the analysis that had been done, either through the questionnaires or interview, this following is the conclusion which made by writer. This conclusion is also the answers of all the problem formulation which are the goals of writer to conduct this study. Tanjung Pinang Chinese Students at Binus University maintain their vernacular language through three ways. The first way is by keeping contact with family in hometown which makes them still use their vernacular while communicating with family members in homeland. The second way is by keeping the use of vernacular in Jakarta with friends who are coming from the same homeland, or those who share the same vernacular even though they are not coming from the same hometown. In other words, the second way of these Tanjung Pinang Chinese Students maintain their vernacular language is by still using it even they have been living in Jakarta with friends who can speak their vernacular. The third way is by showing respect towards their vernacular as it is really important for the language maintenance. Most of the participants really respect their vernacular by seeing it as the cultural wealth that shall be preserved and their willingness to inherit the vernacular to their descendants for the sake of preserving this cultural wealth and identity.

In addition, there are several factors is affecting Tanjung Pinang Chinese Students to maintain their vernacular. This finding was in line with previous study [7]. The first one is their point of view towards the vernacular language, in which this is including how they define the vernacular and then commit to preserve and inherit the vernacular based on their definition towards the vernacular. The second factor that provokes their intention and willingness to preserve the vernacular is because of communicating using vernacular is already becoming their habit, which also becoming the factor that affect these participants in maintaining the language. Consequently, without they realize it or not, as long as they continue to use the vernacular, it also means that they are maintaining it. The third factor is family ties, including: family living close to one another and still keeping contact with their family at their hometown; frequent contact with homeland in which they meet and communicate with people from homeland when they back to hometown during the holidays or semester break. Other activities, ones they have in Bina Nusantara Mandarin Club (BNMC) allow them to communicate using the vernacular.

The last factor is following Holmes' (2008) idea of ethnolinguistics vitality components that support language maintenance. The first component is attitude towards the language, in which most of the participants really respect their vernacular language. The second component is the language distribution which is wide vernacular language distribution. The third component is the institutional support that the language enjoys, which is very strong institutional support (following Article 32 Paragraph 2 of Indonesian Constitution). 
All in all, it is concluded that most of the participants in this research are truly respecting the vernacular language and feel comfortable in using it, which is seen despite there are many more appealing majority and prestigious language, they still choose to use their vernacular. Moreover, it is also seen that they are very proud with their vernacular by defining it as their identity and cultural that have to be preserved and commit to inherit it to the offspring. Throughout the analysis and theories towards this research, the writer finally draws up that a language value is actually depends on how the speakers define it, in other words it is depends on the speakers attitude towards it. A language will become stronger when there is more people speak it, therefore language maintenance is really lean on the speakers' awareness, willingness, and intention to maintain and inherit it.

Meanwhile, for those who will do further study about language maintenance, the writer suggests them to do longer observation for more complex results. Besides, they can attach some literature reviews about language policy to support the research for vivid result.

\section{REFERENCES}

[1] Elbow, P. 2012. Vernacular Eloquence: What Speech Can Bring to Writing. Oxford University Press. Retrieved May 23, 2015 from

http://www.grammer.about.com/od/tz/verna cularterm.htm.

[2] Holmes, J. 2008. An introduction to sociolinguistics (3rd Ed.). New York: Pearson Education ESL.

[3] Finegan, E. 2004. Language: Its structure and use. Boston: Thomson Wadsworth.

[4] Fishman, J.A. 1972. Language in Sociocultural Change. Stanford: Stanford University Press.

[5] Davies, A., Elder, C. 2004. The Handbook of Applied Linguistics. Malden: Blackwell Publishing.

[6] Fishman, J.A. 1993. The Earliest Stage of Language Planning: The First Congress Phenomenon. Boston: De Gruyter Mouton.

[7] Giles, H. 1977. Language, Ethnicity and Intergroup Relations. Michigan: Academic Press.

[8] Ngadini, V. 2007. Language Maintenance of Chinese Language in Glodok Area. Language Maintenance. Retrieved May 20, 2015 from http://library.binus.ac.id/Thesis/RelatedSubj ect/2007-1-00161-IG.
[9] Wihardja, D. 2007. Language Shift and Maintenance of Pontianak Chinese: A Case Study of Fifty Bina Nusantara Students. Language Maintenance. Retrieved May 20, 2015 from http://library.binus.ac.id/Thesis/RelatedSubj ect/2007-3-00206-IG.

[10] Johnston, W.R. 2015. Language: A Definition from First Principles - Three Grand Over the Truckstop. Philica. 10, from http://www.philica.com/display_article.php? article id=136.

[11] Lim, H., Mead, D. 2011. Chinese in Indonesia: A Background Study. Texas: SIL International.

[12] Mesthrie, R., Swann, J., Deumert, A., Leap, W. L. 2000. Introduction Sociolinguistics. Edinburgh: Edinburgh University Press.

[13] Qiu, Gui Su. 2016. Chinese Language. Retrieved September 2, 2016 from http://mandarin.about.com/od/mandarininchi neseculture/a/chinese_language.htm. 